\title{
Dexamethasone interferes with trastuzumab-induced cell growth inhibition through restoration of AKT activity in BT-474 breast cancer cells
}

\author{
TAKASHI SUMIKAWA, YASUSHI SHIGEOKA, TADASHI IGISHI, HISASHI SUYAMA, AKIRA YAMASAKI, \\ KIYOSHI HASHIMOTO, SHINGO MATSUMOTO, KENICHI TAKEDA, YASUTO UEDA and EIJI SHIMIZU \\ Division of Medical Oncology and Molecular Respirology, Faculty of Medicine, \\ Tottori University, Yonago 683-8504, Japan
}

Received October 15, 2007; Accepted December 10, 2007

\begin{abstract}
The combination of trastuzumab with paclitaxel (PTX) is an important option for the treatment of HER2positive breast cancer. Dexamethasone (Dex) premedication is routinely used in the treatment with PTX. The interactions among Dex, PTX and trastuzumab were evaluated in BT-474 cells. Dex interfered with trastuzumab-induced cell growth inhibition without clear effects on PTX-induced cytotoxicity. Trastuzumab dephosphorylated retinoblastoma protein (pRB). Dex restored this trastuzumab-induced dephosphorylation of pRB and released trastuzumab-induced $\mathrm{G}_{1}$ arrest. Trastuzumab suppressed AKT activity without affecting ERK activity. A specific inhibitor for the phosphatidylinositol 3-kinase/AKT pathway, LY294002, inhibited cell growth and AKT and pRB phosphorylation. Dex restored the trastuzumab-induced suppression of AKT without affecting ERK activity. It was concluded that Dex interferes with trastuzumab-induced cell growth inhibition, at least partially, through the restoration of trastuzumab-induced AKT suppression and subsequent pRB dephosphorylation in BT-474 breast cancer cells. These observations support the development of new chemotherapeutic regimens without glucocorticoid premedication.
\end{abstract}

\section{Introduction}

HER2 is over-expressed in $20-30 \%$ of breast cancer, and has been proposed to be related to cell growth and survival (1). A humanized IgG1 monoclonal antibody that recognizes an epitope in the extracellular domain of HER2, trastuzumab (Herceptin ${ }^{\circledR}$ ) is used in the treatment of HER2-positive breast cancer (2). Clinical studies have been established showing that trastuzumab is active against HER2-overexpressing metastatic breast cancers (MBC) either in combination with

Correspondence to: Dr Tadashi Igishi, Division of Medical Oncology and Molecular Respirology, Faculty of Medicine, Tottori University, Yonago 683-8504, Japan

E-mail: igishi@grape.med.tottori-u.ac.jp

Key words: breast cancer, trastuzumab, dexamethasone, AKT chemotherapeutic agents $(3-6)$ or alone $(7,8)$. Among cytotoxic drugs combined with trastuzumab, paclitaxel (PTX) is a major chemotherapeutic agent for the treatment of MBC (1). Furthermore, as post operative chemotherapy in HER2positive breast cancer, the combination of trastuzumab with PTX is recommended after treatment with doxorubicin and cyclophosphamide (9). Accordingly, the combination of trastuzumab with PTX is an important option for the treatment of breast cancer.

In the clinical use of PTX, a hypersensitivity reaction is one of the major adverse events (10). Glucocorticoids, including dexamethasone (Dex), are used to prevent these reactions $(11,12)$. Because Dex premedication is routinely used in the treatment with PTX, the effect of Dex on PTX-induced cytotoxicity is an important issue. In this regard, Wu et al reported that the treatment with Dex decreases the cytotoxicity by PTX through NF- $\mathrm{KB}$ inhibition in breast cancer cell lines (13). Similarly, we reported antagonistic effects of Dex on PTX-induced cytotoxicity through inhibition of the cell cycle progression in non-small cell lung cancer cell lines (14).

Since the combination of PTX and trastuzumab is frequently utilized in the treatment of breast cancer, trastuzumab is deservedly used concomitantly with Dex. However, there have been few findings on the interaction between trastuzumab and Dex. In the process of evaluating the effect of Dex on cell growth inhibition of the combination of PTX and trastuzumab in breast cancer cells, we found that Dex strongly interferes with the trastuzumab-induced cytostatic effect rather than with the cytotoxicity of PTX. Here, we report that Dex precludes trastuzumab-induced cell growth inhibition through activation of the AKT pathway in HER2over-expressing BT-474 breast cancer cell lines.

\section{Materials and methods}

Chemicals and reagents. Trastuzumab (Chugai Pharmaceutical Co., Tokyo, Japan) was diluted in distillated water and stored at $-80^{\circ} \mathrm{C}$. PTX (a gift from Bristol-Myers-Squibb, Tokyo, Japan) and 2-(4-morpholinyl)-8-phenyl-4H-1-benzopyran-4one (LY294002) (Sigma-Aldrich Japan, Tokyo, Japan) were dissolved in dimethylsulfoxide and stored at $-20^{\circ} \mathrm{C}$. Dex (Wako Pure Chemical Industries, Osaka, Japan) was dissolved 
in dimethylsulfoxide and stored at $-80^{\circ} \mathrm{C}$. 3-(4,5-dimethylthiazol-2-yl)-2,5-diphenyltetrazolium bromide (MTT) (Sigma Chemical Co., St. Louis, MO) was dissolved in phosphatebuffered saline (PBS) and stored at $-20^{\circ} \mathrm{C}$.

Cell lines and cultures. Human breast cancer cell lines, BT-474 cells, were obtained from American Type Culture Collection (Manassas, VA). The BT-474 cell lines were maintained in RPMI-1640 supplemented with $10 \%$ fetal bovine serum (FBS) and antibiotics. The cells were grown in a humidified atmosphere of $5 \% \mathrm{CO}_{2}-95 \%$ air.

MTT assay. The growth inhibitory effects of these chemotherapeutic agents were estimated by an MTT assay. BT-474 cells were counted with a hematocytometer and $6 \times 10^{3}$ cells were incubated in $100 \mu 1$ medium containing various concentrations of Dex, PTX and trastuzumab for $72 \mathrm{~h}$ using 96-well flat bottom multiplates (BD Falcon, Franklin, NJ). The plates were incubated under the same conditions for the indicated time. After the indicated treatment, MTT solution $(10 \mathrm{mg} / \mathrm{ml}$ in PBS) was added $(10 \mu \mathrm{l} /$ well). The plates were further incubated for $4 \mathrm{~h}$ at $37^{\circ} \mathrm{C}$. Thereafter, the formazan crystals formed were dissolved by adding $100 \mu 1$ of $0.04 \mathrm{~N} \mathrm{HCl}$ in 2propanol. Absorption was measured by a microplate reader (MPR-A4i; Tosoh Corp., Tokyo, Japan) at $570 \mathrm{~nm}$ (reference filter $650 \mathrm{~nm}$ ). Measurements were performed in triplicate. DMEM $(100 \mu \mathrm{l})$ with $10 \mu \mathrm{l}$ MTT-solution and $100 \mu \mathrm{l} 2$ propanol was used as blank solution.

Cell lysis, immunoprecipitation, and Western blot analysis. The BT-474 cells were lysed in a modified radioimmune precipitation buffer ( $1 \%$ Triton $\mathrm{X}-100,0.1 \%$ SDS, $0.1 \%$ sodium deoxycholate, $100 \mathrm{mM} \mathrm{NaCl}, 10 \mathrm{mM}$ Tris-HCl, pH 7.5, $2 \mathrm{mM}$ EDTA, $10 \mu \mathrm{g} / \mathrm{ml}$ leupeptin, $1 \mathrm{mM}$ phenylmethyl-sulfonyl fluoride, $10 \mathrm{mM} \mathrm{NaF}, 40 \mathrm{mM} ß$-glycerophosphate, and $2 \mathrm{mM}$ $\mathrm{Na}_{3} \mathrm{VO}_{4}$ ), and the insoluble material was removed by centrifugation. The protein concentration was determined by means of a Bio-Rad protein assay (Bio-Rad, CA) and lysates containing $50 \mu \mathrm{g}$ of total cellular protein or immunoprecipitates with the indicated antibodies were analyzed by Western blotting after SDS-polyacrylamide gel electrophoresis and visualized by enhanced chemiluminescence detection (Amersham Pharmacia Biotech) using goat antirabbit or anti-mouse IgGs coupled with horseradish peroxidase as a secondary antibody (Amersham Pharmacia Biotech). Antibodies against retinoblastoma protein (pRB) were purchased from Santa Cruz Biotechnology (IF8 for immunoprecipitation) and Cell Signaling Technology (4H1 for Western blot analysis. Anti-ERK1/2 and anti-active ERK1/2 (p-ERK1/2) antibodies were purchased from Promega Corp.. Anti-AKT and anti-active AKT (p-AKT) antibodies were purchased from Cell Signaling Technology. An anti- $\beta$-actin antibody was obtained from Sigma-Aldrich Japan.

Bromodeoxyuridine incorporation studies. Measurement of the rate of proliferation was performed by determining nucleotide incorporation into DNA (15). The BT-474 cells were incubated for $24 \mathrm{~h}$ in $1 \mathrm{ml}$ of medium containing 10\% FBS using 60-mm dishes. After $24 \mathrm{~h}$, the growth media was removed. The BT-474 cells were treated with $2 \mu \mathrm{M}$ of Dex, $10 \mu \mathrm{g} / \mathrm{ml}$ of trastuzumab, or their combination for $72 \mathrm{~h}$. Then $10 \mu \mathrm{M}$ of bromodeoxyuridine (BrdU) was added into the solution $4 \mathrm{~h}$ before the analysis. After these treatments, the cells were washed, collected by trypsinization and re-suspended in 1-ml PBS. The cells were fixed in ice-cold $70 \%$ ethanol overnight at $-20^{\circ} \mathrm{C}$. The fixed cells were washed with PBS and then mixed with $4 \mathrm{M} \mathrm{HCl}$ containing $0.5 \%$ Triton-X. After $30 \mathrm{~min}$ at room temperature, the cells were washed with PBS and neutralized by $0.1 \mathrm{M}$ sodium tetraborate ( $\mathrm{pH} 8.5$ ). Then FITC conjugated anti-BrdU antibody was added to the cells for $2 \mathrm{~h}$ at room temperature in the dark. After a wash step, the cells were treated with $1 \mathrm{ml}$ of propidium iodide solution $(10 \mu \mathrm{g} / \mathrm{ml}$ of propidium iodide, $20 \mathrm{mM}$ EDTA, 0.05\% Tween-20, $50 \mu \mathrm{g} / \mathrm{ml}$ RNase). Cell fluorescence was analyzed by a Becton FACScan using cell Quest software (Becton Dickinson, Mountain View, CA).

\section{Results}

The effects of trastuzumab, PTX and Dex on the proliferation in BT-474 cells. The BT-474 cells were treated with various concentrations of trastuzumab and PTX concurrently for $72 \mathrm{~h}$ and growth inhibition was assessed by MTT assay. As shown in Fig. 1A, the combination effects of trastuzumab and PTX were additive. In the clinical utilization of trastuzumab and PTX, Dex must be used to avoid hypersensitivity reactions. Hence, we investigated the effects of Dex on PTX- and trastuzumab-induced cell growth inhibition. The BT-474 cells were treated with PTX or trastuzumab for $72 \mathrm{~h}$ in the presence of various concentrations of Dex. Clear effects of DEX on PTX-induced growth inhibition were not observed in the combination of Dex and PTX. However, in the combination of Dex and trastuzumab, Dex interfered with the trastuzumabinduced growth inhibition in a concentration-dependent manner (Fig. 1B).

In preliminary experiments, treatments with $1 \mu \mathrm{g} / \mathrm{ml}$ of trastuzumab, the combination of $0.5 \mu \mathrm{g} / \mathrm{ml}$ of trastuzumab and $1 \mathrm{nM}$ of PTX or $10 \mathrm{nM}$ of PTX for $72 \mathrm{~h}$ exerted $50 \%$ growth inhibition activity in BT-474 cells. To compare the effects of Dex on trastuzumab- and PTX-induced growth inhibition, various concentrations of Dex were combined with these treatments (Fig. 1C). As shown, the effects of Dex were marginal in the treatment with PTX alone, and the interference by Dex to growth inhibition increased in the order of the treatment with trastuzumab alone, trastuzumab and PTX, and PTX alone. We concluded that trastuzumabinduced growth inhibition is affected more strongly than that by PTX in BT-474 cells.

Effects of trastuzumab and Dex on the cell cycle progression in BT-474 cells. For the purpose of linking cell cycle distribution and the biological response to Dex and trastuzumab, we performed DNA content analysis by propidium iodide staining using BrdU in BT-474 cells. BT-474 cells were treated with $10 \mu \mathrm{g} / \mathrm{ml}$ of trastuzumab, $2 \mu \mathrm{M}$ of Dex or their combination for $72 \mathrm{~h}$. BrdU was added during the last $4 \mathrm{~h}$ before the analysis. DNA ploidy analysis by flow cytometry is shown in Fig. 2A. After $10 \mu \mathrm{g} / \mathrm{ml}$ of trastuzumab treatment for $72 \mathrm{~h}$, cells in the $G_{1}$ and $S$ phases increased and decreased, respectively, indicating $G_{1}$ arrest induced by trastuzumab. 
A

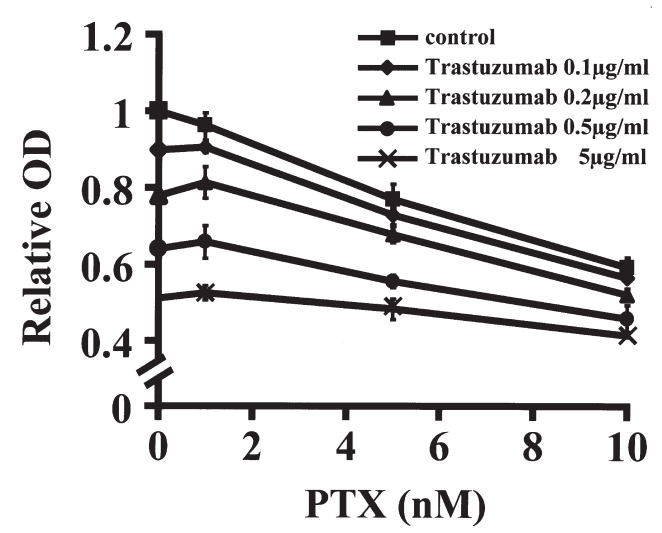

C

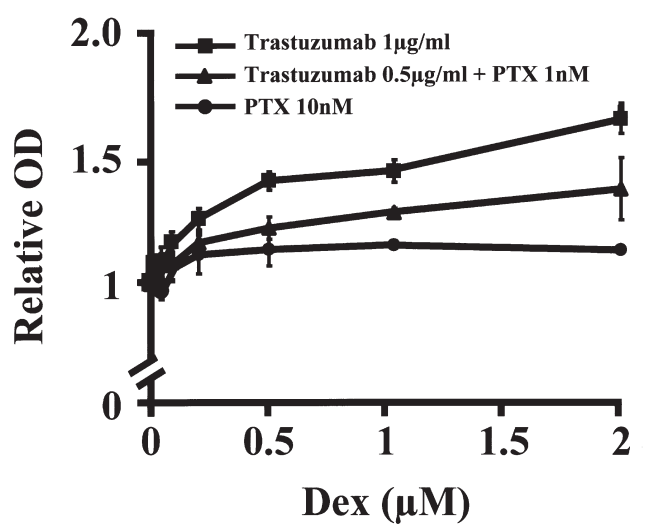

B
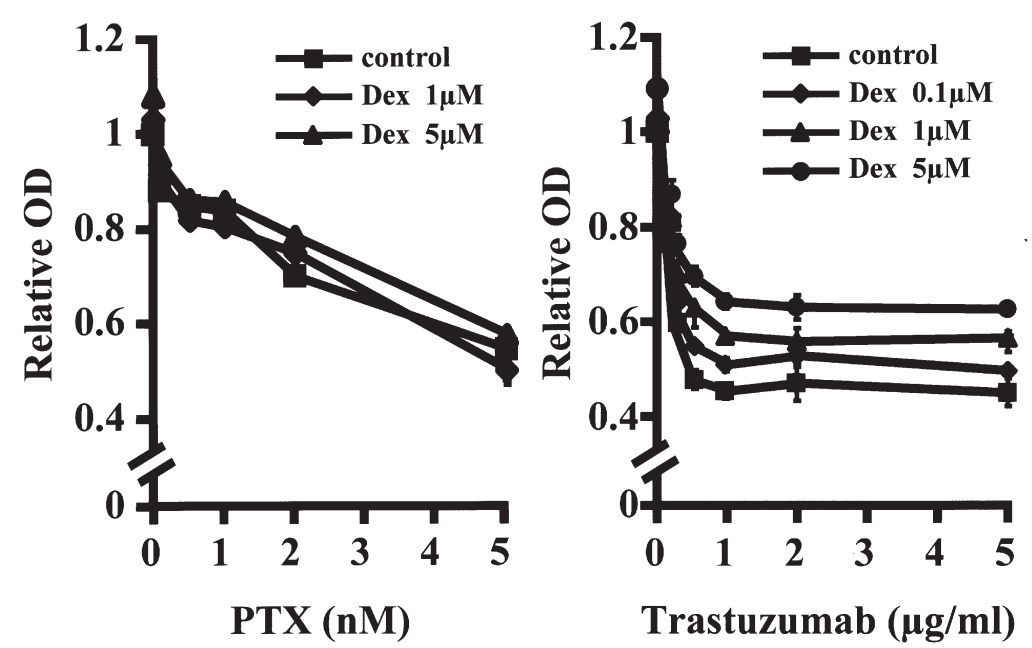

Figure 1. Interference of dexamethasone (Dex) to the trastuzumab-induced cell growth inhibition. BT-474 cells were treated with the combinations of (A) trastuzumab and paclitaxel (PTX), (B) PTX and Dex (left panel), or trastuzumab and Dex (right panel) for $72 \mathrm{~h}$. The cell count was assessed by MTT assay and expressed as the relative optical density (OD) in reference to that of untreated control cells. (C) BT-474 cells were treated with various concentrations of Dex in the presence of trastuzumab $(1 \mu \mathrm{g} / \mathrm{ml})$ alone, trastuzumab $(0.5 \mu \mathrm{g} / \mathrm{ml})$ and PTX $(1 \mathrm{nM})$, or PTX $(10 \mathrm{nM})$ alone for $72 \mathrm{~h}$. The survival cell fraction was expressed as the relative OD in reference to that of the Dex-untreated cells. Data are presented as the mean \pm standard deviation of three separate experiments.

The combination of trastuzumab with Dex decreased and increased cells in the $G_{1}$ and $S$ phases, respectively, compared with those of the trastuzumab alone. These results indicate that Dex interferes with trastuzumab-induced $\mathrm{G}_{1}$ arrest.

To clarify the underlying biochemical mechanism by which Dex perturbs trastuzumab-induced $\mathrm{G}_{1}$ arrest, we investigated the effects of trastuzumab, Dex and the combination of these agents on retinoblastoma protein (pRB) phosphorylation.

As shown in Fig. 2B, the treatment of BT-474 cells with $10 \mu \mathrm{g} / \mathrm{ml}$ of trastuzumab dephosphorylated pRB in a timedependent manner. Thus, BT-474 cells were treated with $10 \mu \mathrm{g} / \mathrm{ml}$ of trastuzumab, $2 \mu \mathrm{M}$ of Dex or their combination for $72 \mathrm{~h}$ (Fig. 2C). The pRB was dephosphorylated clearly when the cells were treated with $10 \mu \mathrm{g} / \mathrm{ml}$ of trastuzumab alone for $72 \mathrm{~h}$. Although Dex alone did not affect pRB phosphorylation, the combination of Dex and trastuzumab restored the phosphorylation level of $\mathrm{pRB}$ to a considerable extent. Taken together, the interference of Dex to trastuzumabinduced growth inhibition is attributable to release of the trastuzumab-induced $\mathrm{G}_{1}$ arrest through the restoration of $\mathrm{pRB}$ phosphorylation by Dex.
Effects of trastuzumab and Dex on the activity of AKT and ERK in BT-474 cells. To understand the signaling route that leads to pRB dephosphorylation by trastuzumab, the active form of ERK and AKT were evaluated by Western blotting after treatment with various concentrations of trastuzumab for the indicated time (Fig. 3A). As shown, $10 \mu \mathrm{g} / \mathrm{ml}$ of trastuzumab reduced AKT phosphorylation after 12-24 h, and this dephosphorylation was maintained thereafter. A concentration-dependent suppression of AKT phosphorylation was also observed. However, ERK phosphorylation did not change in the range of trastuzumab treatments tested ( $\leq 10 \mu \mathrm{g} / \mathrm{ml}$ of trastuzumab for $72 \mathrm{~h}$ ) (Fig. 3A).

To confirm that the trastuzumab-induced cell growth inhibition is attributable to AKT inhibition, the effects of a specific inhibitor for the phosphatidylinositol 3-kinase (PI3K)/ AKT pathway, LY294002, on AKT and pRB phosphorylation and cell growth were evaluated. The treatment with $25 \mu \mathrm{M}$ of LY294002 clearly inhibited AKT and pRB phosphorylation (Fig. 3B), and cell growth (Fig. 3C) in BT-474 cells.

Effects of Dex on trastuzumab-induced AKT dephosphorylation in BT-474 cells. BT-474 cells were treated with $10 \mu \mathrm{g} / \mathrm{ml}$ of 


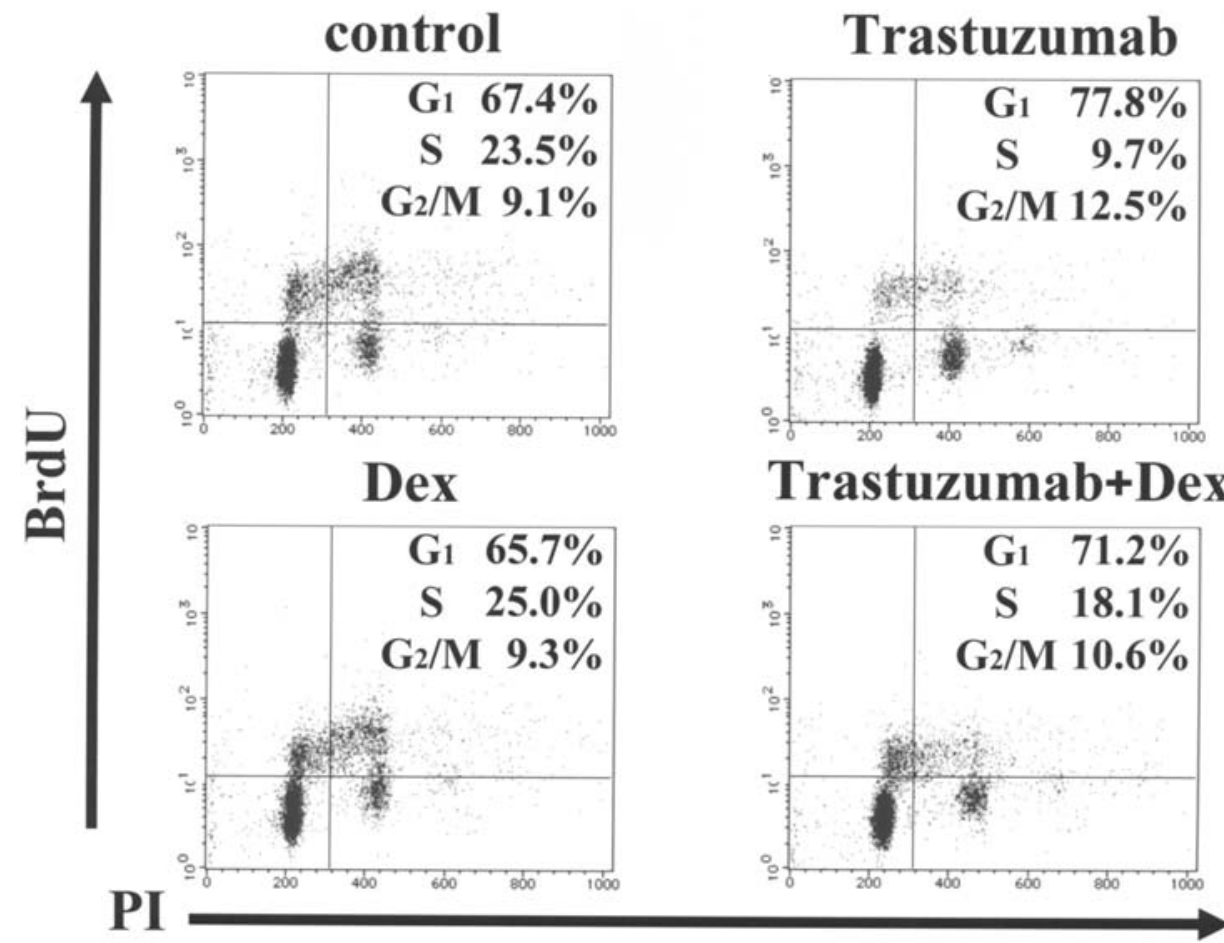

B

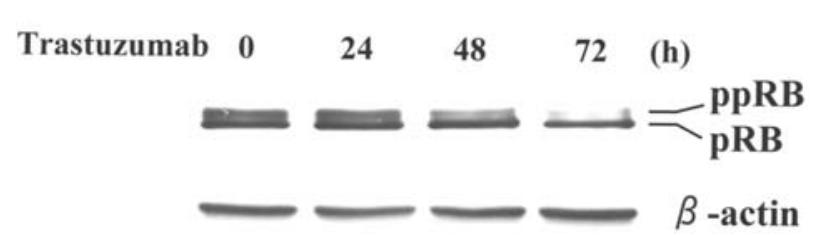

C Trastuzumab - $+\quad+$

Dex

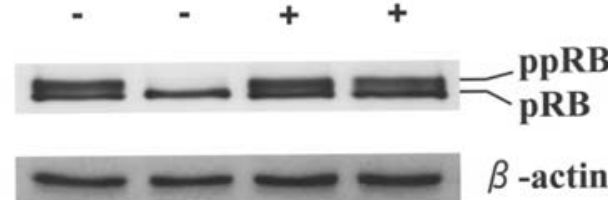

Figure 2. Effects of trastuzumab and dexamethasone (Dex) on the cell cycle progression in BT-474 cells. (A) BT-474 cells were treated with normal medium, $10 \mu \mathrm{g} / \mathrm{ml}$ of trastuzumab, $2 \mu \mathrm{M}$ of Dex or their combination for $72 \mathrm{~h}$. Ten micromolars of BrdU were added during the last $4 \mathrm{~h}$ before the analysis. The cells were fixed, stained and analyzed as described in Materials and methods. Representative scatter plots with the log FITC anti-bromodeoxyuridine (BrdU) staining versus propidium iodide (PI) staining are shown. The cell cycle distribution of the cells was calculated using the gates in each scatter plot and expressed as a percentage. (B) BT-474 cells were treated with $10 \mu \mathrm{g} / \mathrm{ml}$ of trastuzumab for the indicated time. Retinoblastoma protein (pRB) was immunoprecipitated from $1 \mathrm{mg}$ of total cellular protein by the anti-pRB antibody (IF8) and subjected to Western blot analysis with anti-pRB (4H1) as described in Materials and methods. pRB, hypophosphorylated RB; ppRB, hyperphosphorylated RB. Fifty micrograms of total cellular protein from the same cell lysate were subjected to Western blot analysis with anti-ß-actin antibody. (C) The BT-474 cells were treated with $10 \mu \mathrm{g} / \mathrm{ml}$ of trastuzumab and/or $2 \mu \mathrm{M}$ of Dex for $72 \mathrm{~h}$. Immunoprecipitate with anti-pRB antibody (IF8) or total cellular protein were subjected to Western blot analysis with the anti-pRB (4H1) or anti- $\beta$-actin antibody, respectively. Bands corresponding to hyperphosphorylated RB (ppRB) and hypophosphorylated RB (pRB) are indicated.

trastuzumab for $72 \mathrm{~h}$. Before cell harvest, $2 \mu \mathrm{M}$ of Dex was combined for the indicated time (Fig. 4A). As shown, the treatment with Dex restored trastuzumab-induced AKT dephosphorylation in a time-dependent manner (Fig. 4A). Subsequently, the BT-474 cells were treated with $10 \mu \mathrm{g} / \mathrm{ml}$ of trastuzumab with various concentrations of Dex for $72 \mathrm{~h}$. The trastuzumab-induced dephosphorylation of AKT was clearly restored by the Dex treatment in a concentrationdependent manner (Fig. 4A). Similarly, we evaluated the effects of $10 \mu \mathrm{g} / \mathrm{ml}$ of trastuzumab, $2 \mu \mathrm{M}$ of Dex and their combination on ERK phosphorylation after 72-h treatment (Fig. 4B). A clear effect with these treatments was not observed in terms of ERK phosphorylation.

\section{Discussion}

This in vitro study was carried out in order to clarify the interactions of Dex treatment on the trastuzumab-induced growth inhibition of breast cancer cells and underlying mechanisms by which Dex interferes with the action of trastuzumab. Our observations in the present study suggest that the restoration of AKT, but not ERK, activity by Dex is an important mechanism of its antagonistic effects on trastuzumab-induced growth inhibition.

Using BT-474 cells as a model system of HER2-positive breast cancer, we examined the effects of Dex on the trastuzumab-induced growth inhibition, phosphorylation status of pRB, and the activity of ERK and AKT.

Previous studies, including our research, reported antagonistic effects of Dex on PTX-induced cytotoxicity in breast cancer and lung adenocarcinoma cells $(13,14)$. In the present study, PTX-induced cell growth inhibition was not significantly affected by Dex in BT-474 breast cancer cells, suggesting that this antagonistic effect is cell-specific. On the other hand, we reported here the interference of Dex to trastuzumabinduced growth inhibition in vitro, to our knowledge, for the first time.

Initially, it was believed that trastuzumab exerts antitumor activity in HER2 positive breast cancer through antibody dependent cytotoxicity (16). Recent studies have proposed 
A

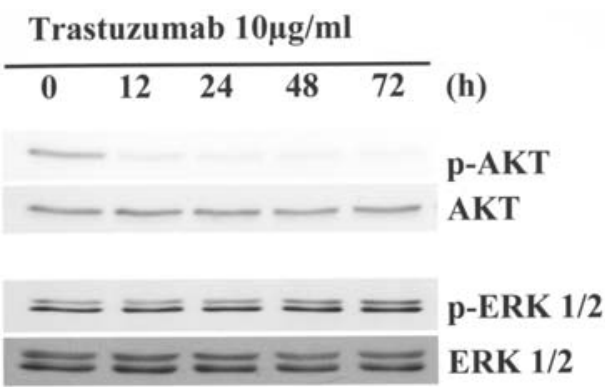

Trastuzumab $72 \mathrm{~h}$

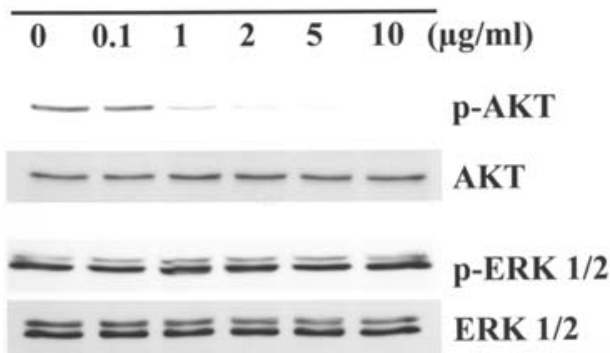

B

control LY

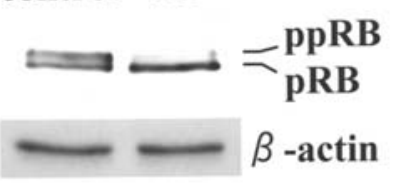

control LY

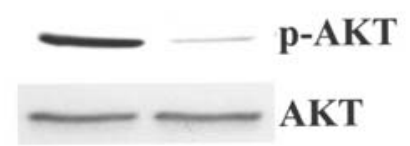

C

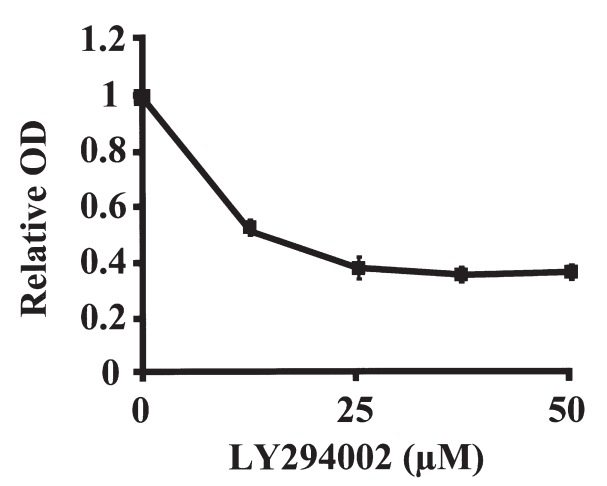

Figure 3. Effects of trastuzumab on the activity of AKT and ERK in BT-474 cells. (A) BT-474 cells were treated with $10 \mu \mathrm{g} / \mathrm{ml}$ of trastuzumab for the indicated time (upper panel) or the indicated concentration of trastuzumab for $72 \mathrm{~h}$ (lower panel). Fifty micrograms of total cellular protein from the cell lysate were subjected to Western blot analysis with anti-active AKT (p-AKT), anti-AKT, anti-active ERK (p-ERK1/2) or anti-ERK1/2 antibody as described in Materials and methods. (B) BT-474 cells were treated with $25 \mu \mathrm{M}$ of LY294002 (LY) for $24 \mathrm{~h}$. Retinoblastoma protein (pRB) was immunoprecipitated from $1 \mathrm{mg}$ of total cellular protein by anti-pRB antibody (IF8) and subjected to Western blot analysis with anti-pRB antibody (4H1) (upper panel). pRB, hypophosphorylated RB; ppRB, hyperphosphorylated RB. Fifty micrograms of total cellular protein from the same cell lysate were subjected to Western blot analysis with anti-ß-actin (upper panel), anti-active AKT (p-AKT) or anti-AKT (lower panel). (C) BT-474 cells were treated with various concentrations of LY294002 (LY) for $72 \mathrm{~h}$. The cell count was assessed by MTT assay and expressed as the relative optical density (OD) in reference to that of untreated control cells. Data are presented as the mean \pm standard deviation of three separate experiments.
A Trastuzumab $10 \mu \mathrm{g} / \mathrm{ml}, 72 \mathrm{~h}$

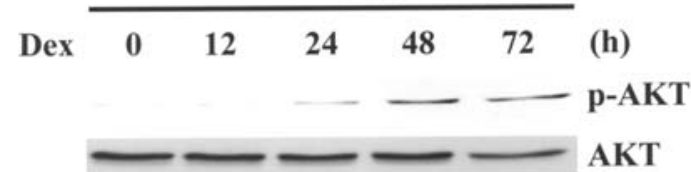

Trastuzumab $10 \mu \mathrm{g} / \mathrm{ml}, 72 \mathrm{~h}$

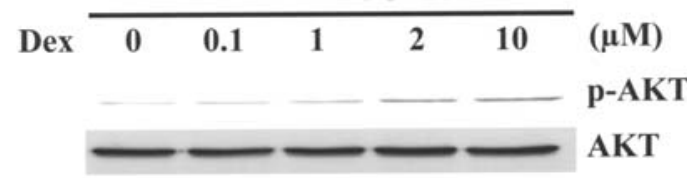

B
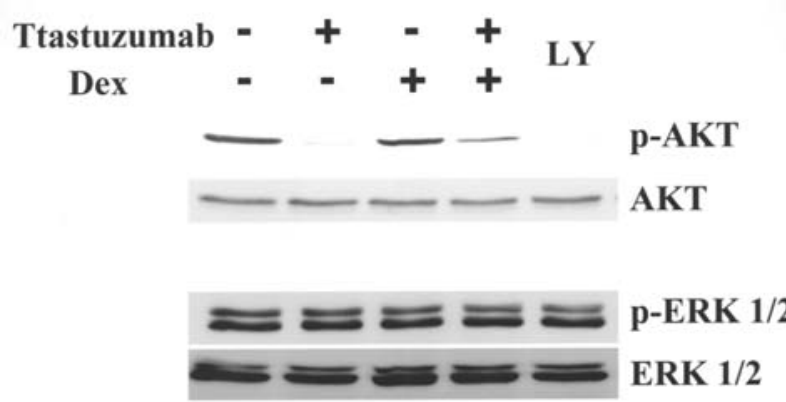

Figure 4. Effects of dexamethasone (Dex) on the activity of AKT and ERK in BT-474 cells. (A) BT-474 cells were treated with $10 \mu \mathrm{g} / \mathrm{ml}$ of trastuzumab for $72 \mathrm{~h}$. Before cell harvest, $2 \mu \mathrm{M}$ (upper panel) or the indicated concentration (lower panel) of Dex were combined for the indicated time or $72 \mathrm{~h}$, respectively. Fifty micrograms of total cellular protein from the cell lysate was subjected to Western blot analysis with antiactive AKT (p-AKT) or anti-AKT antibody. (B) BT-474 cells were treated with $10 \mu \mathrm{g} / \mathrm{ml}$ trastuzumab and/or $2 \mu \mathrm{M}$ Dex, or $25 \mu \mathrm{M} \mathrm{LY} 294002$ (LY) for $72 \mathrm{~h}$. Fifty micrograms of total cellular protein from cell lysate were subjected to Western blot analysis with anti-active AKT (p-AKT) and antiAKT (upper panel) or anti-active ERK (p-ERK1/2) and anti-ERK1/2 antibody (lower panel).

that blockade of the growth promoting intracellular signal from HER2 is an additional important mechanism by which trastuzumab inhibits tumor growth (17).

In general, ERK and AKT are important mediators of cell proliferation signals from receptor tyrosine kinases to $\mathrm{pRB}$ phosphorylation (18). In this study, the treatment of BT-474 cells with trastuzumab inactivated AKT and dephosphorylated pRB without affecting ERK activity, in accordance with previous studies $(19,20)$. Since an AKT inhibitor, LY294002, suppressed cell growth, AKT activity and pRB phosphorylation, trastuzumab-induced cell growth inhibition is, at least partially, attributable to a blockade of signals from AKT to $\mathrm{pRB}$ but not from ERK. AKT suppresses cyclin-dependent kinase $(\mathrm{CDK})$ inhibitors such as $\mathrm{p} 21^{\mathrm{WAF} 1 / \mathrm{CIP} 1}$ and $\mathrm{p} 27^{\mathrm{Kip} 1}$ through phosphorylation $(21,22)$, leading to pRB phosphorylation and cell cycle progression. Thus, the inhibition of these mechanisms by trastuzumab is assumed to function in BT-474 cells.

The administration of 20-mg Dex is recommended when patients are treated with PTX $(10,23)$. When $8 \mathrm{mg}$ of Dex is injected, the concentration of Dex in peripheral blood reaches approximately $1 \mu \mathrm{M}$ (24). Thus, we mainly assessed the effect of $2-\mu \mathrm{M}$ Dex. This clinically relevant concentration of Dex interfered with trastuzumab-induced cell growth suppression and restored the trastuzumab-induced dephosphorylation of 
AKT and pRB to some extent without affecting those in trastuzumab-free conditions. Accordingly, we concluded that the restoration of trastuzumab-induced AKT suppression and subsequent $\mathrm{pRB}$ phosphorylation can be regarded as a main mechanism of the antagonistic effects of Dex on trastuzumab-induced growth inhibition. To clarify the detailed mechanism, it may be necessary to assess the effects of Dex on upstream regulators of AKT such as tyrosine kinases, PI3K, phosphatase and tensin homolog (PTEN) and phosphoinositide-dependent protein kinase (PDK).

As clinical implications of interference of Dex with trastuzumab-induced cytostatic effects, Dex may attenuate the antitumor activity of the combination of trastuzumab and PTX in breast cancer. In addition, glucocorticoid may impair trastuzumab-induced antibody dependent cytotoxicity (16). In this regard, new analogue and formulations of PTX are being developed $(25,26)$, leading to the decrease or removal of the polyoxyethylated castor oil that causes hypersensitivity reactions when using the conventional PTX preparation. Even if these drugs have the same activity against cancer cells as PTX, it may be possible for the omission of glucocorticoid pretreatment to lead to higher effectiveness of the combination treatment with trastuzumab and new generations of taxane. Our observation in this study supports this possibility, and promotes the development of chemotherapies using the new generation of taxane that obviates glucocorticoid premedication in breast cancer.

Furthermore, the observation that Dex restores trastuzumabinduced AKT suppression may have additional implications with respect to chemotherapy in which Dex is utilized as an antiemetic agent. AKT is an important mediator of antiapoptotic intracellular signals (27). The activation of AKT confers resistance against several anticancer agents to cancer cells (28). Since our observations raise the possibility that Dex activates AKT, at least in a fraction of cancer cells, Dex might reduce the effects of some anticancer agents other than trastuzumab and PTX.

In conclusion, the present study demonstrated that the Dex treatment antagonized trastuzumab-induced growth inhibition through the activation of AKT in BT-474 breast cancer cells. These observations support the development of new chemotherapeutic regimens without glucocorticoid premedication.

\section{References}

1. Hudis CA: Trastuzumab-mechanism of action and use in clinical practice. N Engl J Med 357: 39-51, 2007.

2. Leonard DS, Hill AD, Kelly L, et al: Anti-human epidermal growth factor receptor 2 monoclonal antibody therapy for breast cancer. Br J Surg 89: 262-271, 2002.

3. Marty M, Cognetti F, Maraninchi D, et al: Randomized phase II trial of the efficacy and safety of trastuzumab combined with docetaxel in patients with human epidermal growth factor receptor 2-positive metastatic breast cancer administered as first-line treatment: the M77001 study group. J Clin Oncol 23: 4265-4274, 2005.

4. Osoba D, Slamon DJ, Burchmore M, et al: Effects on quality of life of combined trastuzumab and chemotherapy in women with metastatic breast cancer. J Clin Oncol 20: 3106-3113, 2002.

5. Slamon DJ, Leyland-Jones B, Shak S, et al: Use of chemotherapy plus a monoclonal antibody against HER2 for metastatic breast cancer that overexpresses HER2. N Engl J Med 344: 783-792, 2001.
6. Esteva FJ, Valero V, Booser D, et al: Phase II study of weekly docetaxel and trastuzumab for patients with HER-2-overexpressing metastatic breast cancer. J Clin Oncol 20: 1800-1808, 2002.

7. Vogel CL, Cobleigh MA, Tripathy D, et al: Efficacy and safety of trastuzumab as a single agent in first-line treatment of HER2overexpressing metastatic breast cancer. J Clin Oncol 20: 719-726, 2002.

8. Baselga J, Carbonell X, Castaneda-Soto NJ, et al: Phase II study of efficacy, safety, and pharmacokinetics of trastuzumab monotherapy administered on a 3-weekly schedule. J Clin Oncol 23: 2162-2171, 2005

9. Romond EH, Perez EA, Bryant J, et al: Trastuzumab plus adjuvant chemotherapy for operable HER2-positive breast cancer. N Engl J Med 353: 1673-1684, 2005.

10. Weiss RB, Donehower RC, Wiernik PH, et al: Hypersensitivity reactions from taxol. J Clin Oncol 8: 1263-1268, 1990.

11. Gennari A, Salvadori B, Tognoni A, et al: Rapid intravenous premedication with dexamethasone prevents hypersensitivity reactions to paclitaxel. Ann Oncol 7: 978-979, 1996.

12. Quock J, Dea G, Tanaka M, et al: Premedication strategy for weekly paclitaxel. Cancer Invest 20: 666-672, 2002.

13. Wu W, Pew T, Zou M, et al: Glucocorticoid receptor-induced MAPK phosphatase-1 (MPK-1) expression inhibits paclitaxelassociated MAPK activation and contributes to breast cancer cell survival. J Biol Chem 280: 4117-4124, 2005.

14. Morita M, Suyama H, Igishi T, et al: Dexamethasone inhibits paclitaxel-induced cytotoxic activity through retinoblastoma protein dephosphorylation in non-small cell lung cancer cells. Int J Oncol 30: 187-192, 2007.

15. Dolbeare F, Beisker W, Pallavicini MG, et al: Cytochemistry for bromodeoxyuridine/DNA analysis: stoichiometry and sensitivity. Cytometry 6: 521-530, 1985

16. Sliwkowski MX, Lofgren JA, Lewis GD, et al: Non-clinical studies addressing the mechanism of action of trastuzumab (Herceptin). Semin Oncol 26: 60-70, 1999.

17. Yarden Y and Sliwkowski MX: Untangling the ErbB signalling network. Nat Rev Mol Cell Biol 2: 127-137, 2001.

18. Harbour JW and Dean DC: Rb function in cell-cycle regulation and apoptosis. Nat Cell Biol 2: E65-E67, 2000.

19. Dubska L, Andera L and Sheard MA: HER2 signaling downregulation by trastuzumab and suppression of the PI3K/Akt pathway: an unexpected effect on TRAIL-induced apoptosis. FEBS Lett 579: 4149-4158, 2005.

20. Lane HA, Beuvink I, Motoyama AB, et al: ErbB2 potentiates breast tumor proliferation through modulation of p27(Kip1)Cdk2 complex formation: receptor overexpression does not determine growth dependency. Mol Cell Biol 20: 3210-3223, 2000 .

21. Brennan P, Babbage JW, Burgering BM, et al: Phosphatidylinositol 3-kinase couples the interleukin-2 receptor to the cell cycle regulator E2F. Immunity 7: 679-689, 1997.

22. Mitsuuchi Y, Johnson SW, Selvakumaran M, et al: The phosphatidylinositol 3-kinase/AKT signal transduction pathway plays a critical role in the expression of $\mathrm{p} 21 \mathrm{WAF} 1 / \mathrm{CIP} 1 / \mathrm{SDI} 1$ induced by cisplatin and paclitaxel. Cancer Res 60: 5390-5394, 2000.

23. Yamada Y, Shirao K, Ohtsu A, et al: Phase II trial of paclitaxel by three-hour infusion for advanced gastric cancer with short premedication for prophylaxis against paclitaxel-associated hypersensitivity reactions. Ann Oncol 12: 1133-1137, 2001.

24. Tsuei SE, Moore RG, Ashley JJ, et al: Disposition of synethetic glucocorticoids. I. Pharmacokinetics of dexamethasone in healthy adults. J Pharmacokinet Biopharm 7: 249-264, 1979.

25. Hidalgo M, Aylesworth C, Hammond LA, et al: Phase I and pharmacokinetic study of BMS-184476, a taxane with greater potency and solubility than paclitaxel. J Clin Oncol 19: 2493-2503, 2001.

26. Gradishar WJ, Tjulandin S, Davidson N, et al: Phase III trial of nanoparticle albumin-bound paclitaxel compared with polyethylated castor oil-based paclitaxel in women with breast cancer. J Clin Oncol 23: 7794-7803, 2005.

27. Maddika S, Ande SR, Panigrahi S, et al: Cell survival, cell death and cell cycle pathways are interconnected: implications for cancer therapy. Drug Resist Updat 10: 13-29, 2007.

28. Koizumi F, Shimoyama T, Taguchi F, et al: Establishment of a human non-small cell lung cancer cell line resistant to gefitinib. Int J Cancer 116: 36-44, 2005. 